\title{
Severe Chlamydia psittaci pneumonia: clinical characteristics and risk factors
}

\author{
Shanshan Su ${ }^{1 \#}$, Xiaoqing Su ${ }^{2 \#}$, Lingping Zhou ${ }^{1 \wedge}$, Pengcheng Lin ${ }^{1}$, Junjie Chen ${ }^{1}$, Chengshui Chen ${ }^{1 \wedge}$, \\ Ying $\mathrm{Zhou}^{1 \wedge}$, Yuping $\mathrm{Li}^{1 \wedge}$ \\ ${ }^{1}$ Department of Pulmonary and Critical Care Medicine, The First Affiliated Hospital of Wenzhou Medical University, Wenzhou, China; \\ ${ }^{2}$ Department of Radiology, The People's Hospital of Pingyang, Wenzhou, China \\ Contributions: (I) Conception and design: C Chen, Y Zhou, Y Li; (II) Administrative support: None; (III) Provision of study materials or patients: \\ None; (IV) Collection and assembly of data: S Su, X Su; (V) Data analysis and interpretation: L Zhou, P Lin, J Chen; (VI) Manuscript writing: All \\ authors; (VII) Final approval of manuscript: All authors. \\ \#These authors contributed equally to this work. \\ Correspondence to: Ying Zhou; Yuping Li. Department of Pulmonary and Critical Care Medicine, The First Affiliated Hospital of Wenzhou Medical \\ University, South Baixiang, Ouhai District, Wenzhou, China. Email: doczhy85302@126.com; wzliyp@163.com.
}

Background: Psittacosis ranges from a mild illness to fulminant severe pneumonia with multi-organ failure. It's crucial to understand the clinical characteristics and identify risk factors for a better outcome.

Methods: We conducted a retrospective analysis designed to identify risk factors for severe Chlamydia psittaci pneumonia (C. psittaci pneumonia) by comparing the clinical characteristics of patients with severe and less severe forms of the disease. Epidemiological, clinical, laboratory, computed tomography (CT) imaging, and outcome data were collected.

Results: We enrolled 27 patients with C. psittaci pneumonia, with a median age of 63 (range, 47-82) years, and 23 of whom (85.2\%) had a history of avian exposure. Dyspnea was seen in 15 patients with severe C. psittaci pneumonia $(100 \%)$, and four in 12 non-severe patients $(33.3 \%)(\mathrm{P}<0.01)$. Compared to nonsevere patients, those with severe C. psittaci pneumonia had significantly higher levels of procalcitonin, urea nitrogen, lactate dehydrogenase, creatine kinase (CK), B natriuretic peptide (BNP), myoglobin, IL-6, and IL-10, as well as lower lymphocyte and CD8+ T cell counts, and $\mathrm{P}_{\mathrm{a}} \mathrm{O}_{2} / \mathrm{F}_{\mathrm{i}} \mathrm{O}_{2}$ ratio. Among patients with severe infection, CT showed that $46.7 \%$ had multi-lobar (more than two lobes) pneumonia, whereas its incidence was $0 \%$ in non-severe patients $(\mathrm{P}=0.01)$. Multivariate analysis revealed that the independent risk factors associated with severe C. psittaci pneumonia were abnormal CK (OR 15.2, 95\% CI: 1.1-204.8, $\mathrm{P}=0.04$ ) and BNP (OR 22.3, 95\% CI: 1.8-281.9, P=0.02).

Conclusions: A history of prior avian exposure in middle-aged patients should serve as a clue in the diagnosis of C. psittaci pneumonia, and patients with its severe form are more likely to develop dyspnea and progress into respiratory failure, with involvement of multiple lung lobes. Abnormal CK and BNP levels are risk factors associated with severe C. psittaci pneumonia.

Keywords: Pneumonia; psittacosis; Chlamydia psittaci; avian exposure

Submitted May 21, 2021. Accepted for publication Jul 13, 2021.

doi: 10.21037/apm-21-1502

View this article at: https://dx.doi.org/10.21037/apm-21-1502

\footnotetext{
^ ORCID: Shanshan Su, 0000-0002-5334-2827; Lingping Zhou, 0000-0003-1718-0880; Chengshui Chen, 0000-0002-4341-0443; Ying Zhou, 0000-0002-4166-0350; Yuping Li, 0000-0002-5833-931X.
} 


\section{Introduction}

Chlamydia psittaci is an obligate intracellular gramnegative bacterium that primarily infects birds but can also cause zoonotic infection in humans, when it is known as psittacosis (1). Transmission to humans often occurs via the inhalation of contaminated aerosols from the excretions of infected birds. The clinical presentation of psittacosis can range from subclinical or an influenza-like illness to fulminant severe pneumonia with multi-organ failure (2-7). It has been estimated that $C$. psittaci is the causative organism of approximately $1 \%$ of cases of communityacquired pneumonia (CAP), when it is known as C. psittaci pneumonia (8). With early identification and appropriate antibiotic therapy, the infection is rarely fatal (9). However, in recent years, fulminant severe $C$. psittaci pneumonia has been described more frequently using metagenomic nextgeneration sequencing (mNGS) in clinical practice $(2,3,10)$, and it is crucial to understand its clinical characteristics and identify its risk factors. There have some case reports or case series reported about clinical manifestations of $C$. psittaci pneumonia, but the sample sizes are limited $(11,12)$. Meanwhile, to the best of our knowledge, there has been little research focusing on the risk factors of severe $C$. psittaci pneumonia.

We conducted a retrospective study comprising 27 patients with $C$. psittaci pneumonia who were diagnosed using mNGS and compared patients with severe pneumonia to those with the non-severe condition, with the aim of investigating the clinical characteristics of severe $C$. psittaci pneumonia and identify its risk factors.

We present the following article in accordance with the STROBE reporting checklist (available at https://dx.doi. org/10.21037/apm-21-1502).

\section{Methods}

\section{Study design}

We conducted a retrospective case review of 27 patients with $C$. psittaci pneumonia admitted to the First Affiliated Hospital of Wenzhou Medical University, a 3,380-bed tertiary teaching hospital located in south of Zhejiang province, China, between July 1, 2018 and November 30, 2020. The demographic data, comorbidities, clinical manifestations, laboratory findings, radiological information, treatment modalities, and outcomes were extracted from the electronic medical records of patients.

\section{Diagnostic criteria}

Owing to the unavailability of commonly used diagnostic tests for psittacosis, such as serological and polymerase chain reaction-based tests, the diagnostic criteria of $C$. psittaci pneumonia was defined as follows: (I) Individuals fulfilling the diagnostic criteria for CAP according to the stated guidelines (13); (II) the presence of specific C. psittaci gene fragments in bronchial alveolar lavage fluid (BALF) samples detected using mNGS, fulfilled the criteria for a positive mNGS result, as described by Miao et al. (14); routine microbiological tests, including blood, sputum, and BALF culture were all negative. The diagnosis of severe CAP (SCAP) was confirmed based on the stated guidelines (13), and rhabdomyolysis was defined as a serum creatine kinase (CK) level higher than 1,000 U/L (15).

\section{$m N G S$}

Using previously described methods, mNGS analyses were completed by BGI Genomics Institute (Shenzhen, China) (14). Briefly, BALF samples $(0.5-3 \mathrm{~mL})$ were collected following standard procedures then agitated at 2,800-3,200 rpm for $30 \mathrm{~min}$. The DNA from $0.3 \mathrm{~mL}$ of each sample was extracted using a TIANamp Micro DNA Kit (DP316, Tiangen Biotech, Beijing, China) following the manufacturer's instructions. DNA libraries were constructed using DNA fragmentation, end-repair, adapter ligation, and PCR amplification. Low-quality and short (length <35 bp) reads were removed to generate highquality sequencing data, and computational subtraction of human host sequences mapped to the human reference genome (hg19) were performed using the Burrows-Wheeler alignment. The remaining data were classified by removing low-complexity reads, and the sequences were aligned to microbial genome databases for bacteria, fungi, viruses, and parasites downloaded from the US National Center for Biotechnology Information (ftp://ftp.ncbi.nlm.nih.gov/ genomes).

\section{Statistical analysis}

Continuous variables are presented as means \pm standard deviation for normal distribution, or as medians $\left(25^{\text {th }}, 75^{\text {th }}\right.$ percentiles) for non-normal distribution, and categorical variables are presented as percentages. Continuous variables were compared using the $t$-test or Mann-Whitney $U$-test and categorical variables were analyzed using the 
Table 1 General characteristics of patients with community-acquired C. psittaci pneumonia

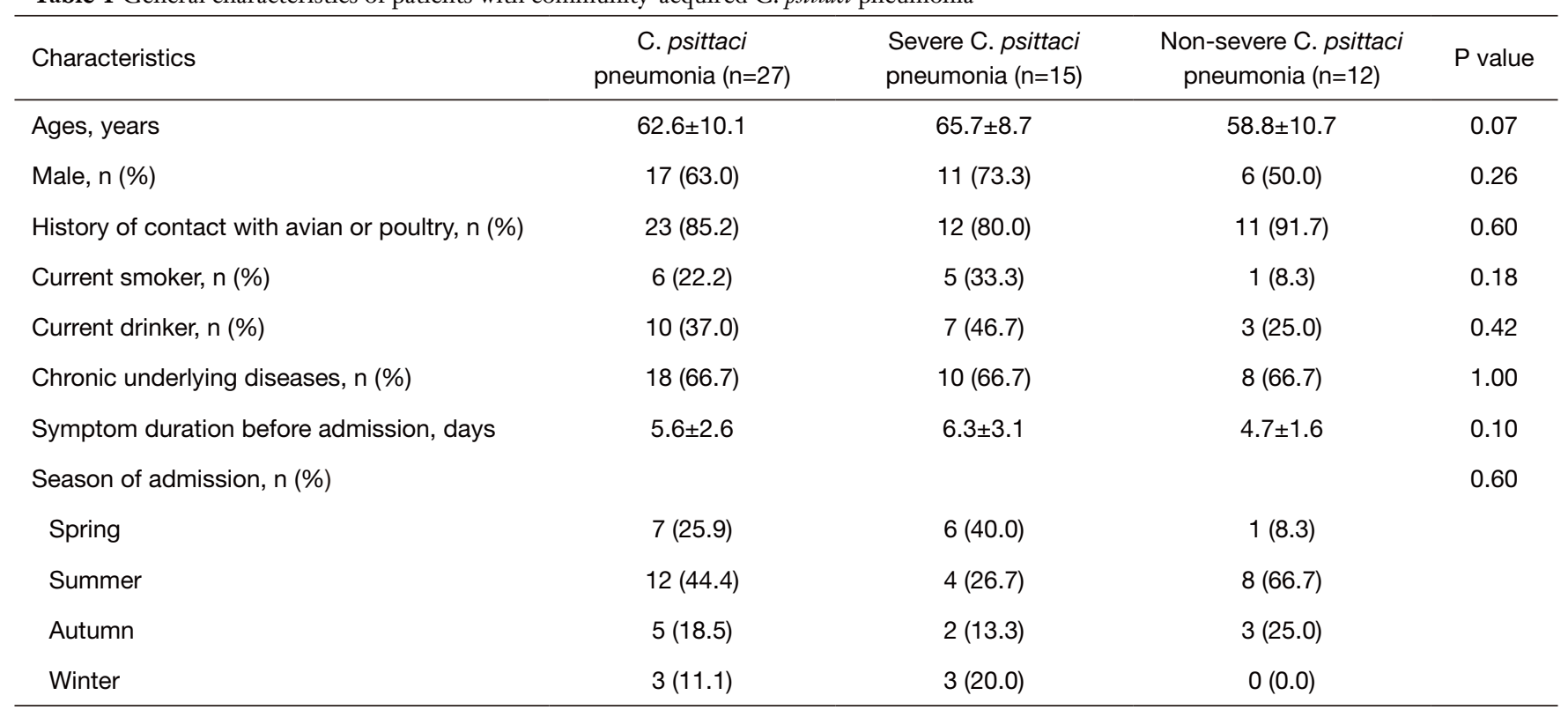

chi-square or Fisher's exact test. Multivariate logistic regression was performed in a stepwise manner to search for independent risk factors associated with severe $C$. psittaci pneumonia. $\mathrm{P}<0.1$ in univariate analysis was considered for the multivariate model, combined with variables that were considered clinically relevant. Variables were carefully chosen to ensure the parsimony of the final model because of the small number of events available. $\mathrm{P}<0.05$ was considered to be statistically significant, and all statistical analyses were performed using SPSS software (version 26.0, SPSS Inc., Chicago).

\section{Ethics approval and consent to participate}

This study received approval from the Ethics Committee of the First Affiliated Hospital of Wenzhou Medical University (No. 2020-111) and was conducted in accordance with the Declaration of Helsinki (as revised in 2013). No informed consent was required due to the retrospective nature of the study.

\section{Results}

\section{General characteristics}

Of the 27 patients, 15 and 12 individuals were diagnosed with severe and non-severe infections, respectively, and $C$. psittaci DNA fragments were detected in BALF samples of all 27 patients using mNGS. Detailed mNGS results are shown in Table S1. Conventional microbiologic examinations, including blood and BALF cultures, did not reveal any other pathogens. Serological tests to detect $\operatorname{IgM}$ and $\operatorname{IgG}$ antibodies for Chlamydophila pneumoniae and Mycoplasma pneumoniae were conducted in 25 patients, revealing one positive result for IgM each for $C$. pneumoniae and $M$. pneumoniae. Eleven patients in both acute and convalescent phases underwent the tests, of which one patient exhibited more than a four-fold increase in $\mathrm{IgG}$ titers for C. pneumoniae. However, DNA fragments of $C$. pneumoniae or $M$. pneumoniae were not detected in these patients using mNGS.

The demographic data and general characteristics of patients are shown in Table 1 . The median age was 63 (range, $47-82$ ) years and 23 of the 27 patients with psittacosis $(85.2 \%)$ had a history of avian exposure. Sixteen patients $(59.3 \%)$ raised poultry, such as chickens and ducks, at home, while five patients raised pigeons and one raised a parrot. One of the patients admitted to visiting live poultry markets. There were no significant differences in general characteristics and underlying diseases between the groups.

\section{Clinical characteristics}

Clinical manifestations of the enrolled patients are shown in Table 2. Patients were febrile with a mean temperature 
Table 2 Clinical manifestations of patients with community-acquired C. psittaci pneumonia

\begin{tabular}{|c|c|c|c|c|}
\hline Characteristics & $\begin{array}{c}\text { C. psittaci } \\
\text { pneumonia }(n=27)\end{array}$ & $\begin{array}{l}\text { Severe C. psittaci } \\
\text { pneumonia }(n=15)\end{array}$ & $\begin{array}{c}\text { Non-severe C. psittaci } \\
\text { pneumonia }(n=12)\end{array}$ & $P$ value \\
\hline Fever, n (\%) & $27(100)$ & $15(100)$ & $12(100)$ & - \\
\hline Temperature, ${ }^{\circ} \mathrm{C}$ & $39.9 \pm 0.5$ & $39.9 \pm 0.5$ & $39.8 \pm 0.5$ & 0.50 \\
\hline Rigors, n (\%) & $18(66.7)$ & $11(73.3)$ & $7(58.3)$ & 0.45 \\
\hline Cough, n (\%) & $22(81.5)$ & $14(93.3)$ & $8(66.7)$ & 0.14 \\
\hline Sputum, n (\%) & $17(63.0)$ & $12(80.0)$ & $5(41.7)$ & 0.06 \\
\hline Dyspnea, n (\%) & $19(70.4)$ & $15(100)$ & $4(33.3)$ & $<0.01$ \\
\hline Gastrointestinal symptoms (vomiting and diarrhea) & $5(18.5)$ & $5(33.3)$ & $0(0.0)$ & 0.05 \\
\hline Rhabdomyolysis & $4(14.8)$ & $3(20.0)$ & $1(8.3)$ & 0.60 \\
\hline
\end{tabular}

of $39.9{ }^{\circ} \mathrm{C}$. Fifteen patients (100\%) with severe C. psittaci pneumonia had dyspnea whereas it was present in only four (33.3\%) patients with the non-severe condition $(\mathrm{P}<0.01)$. Except for dyspnea, patients in both groups had similar symptoms which were not significantly different.

Laboratory results conducted upon admission are shown in Table 3. Compared to patients with the non-severe infection, those with severe $C$. psittaci pneumonia exhibited significantly lower lymphocyte and CD8+ T cell counts, and $\mathrm{P}_{\mathrm{a}} \mathrm{O}_{2} / \mathrm{F}_{\mathrm{i}} \mathrm{O}_{2}$ ratio. Procalcitonin (PCT), urea nitrogen, lactate dehydrogenase ( $\mathrm{LDH}), \mathrm{CK}, \mathrm{B}$ natriuretic peptide (BNP), and myoglobin levels were significantly higher in patients with the severe condition than in those with the non-severe variant. While serum IL-6 and IL-10 levels were significantly higher in patients with severe infection than in those with non-severe infections, white blood cell (WBC) count and C-reactive protein (CRP) levels were not significantly different between the groups.

The radiological manifestations observed during admission are shown in Table 4. Using CT, we found that $46.7 \%$ of patients with the severe condition had multi-lobar pneumonia (more than two lobes) whereas this condition was not observed in patients with non-severe infections. Consolidation was detected in all patients, and inflammatory exudates, groundglass opacities, bronchiectasis, and lymphadenopathy were common in patients in both groups without any significant differences (Figures 1,2). It is noteworthy that pleural effusion was found in 20 of 27 patients $(74.1 \%)$ with C. psittaci pneumonia and presented mostly with unilateral small pleural effusions.

\section{Treatment and outcomes}

The antimicrobial treatments used are listed in Table 5. Antibiotics that were not active against $C$. psittaci were administered empirically on admission to $11.5 \%$ of patients with psittacosis. While one patient with severe disease received carbapenem as the initial empirical antibiotic and developed acute kidney failure, he refused hemodialysis owing to financial constraints and succumbed within 24 hours before receiving the $\mathrm{mNGS}$ result. Quinolone (moxifloxacin, $0.4 \mathrm{~g}$ intravenously q.d.) was administered to $65.4 \%$ of patients, and the median fever-clearance time in the severe group ( 3.5 days) did not significantly differ from that in the non-severe group (2.5 days). Eight patients with the severe form of the infection $(53.3 \%)$ underwent invasive ventilation. And patients in severe group had a higher pneumonia severity index (PSI) than the non-severe patients. About $86.7 \%$ of patients with severe infection developed sepsis whereas there were no instances of sepsis in the non-severe group. The median length of hospital stay was longer in the severe group (12 days) than in the non-severe group (7.5 days). 
Table 3 Laboratory findings on admission of patients with community-acquired C. psittaci pneumonia

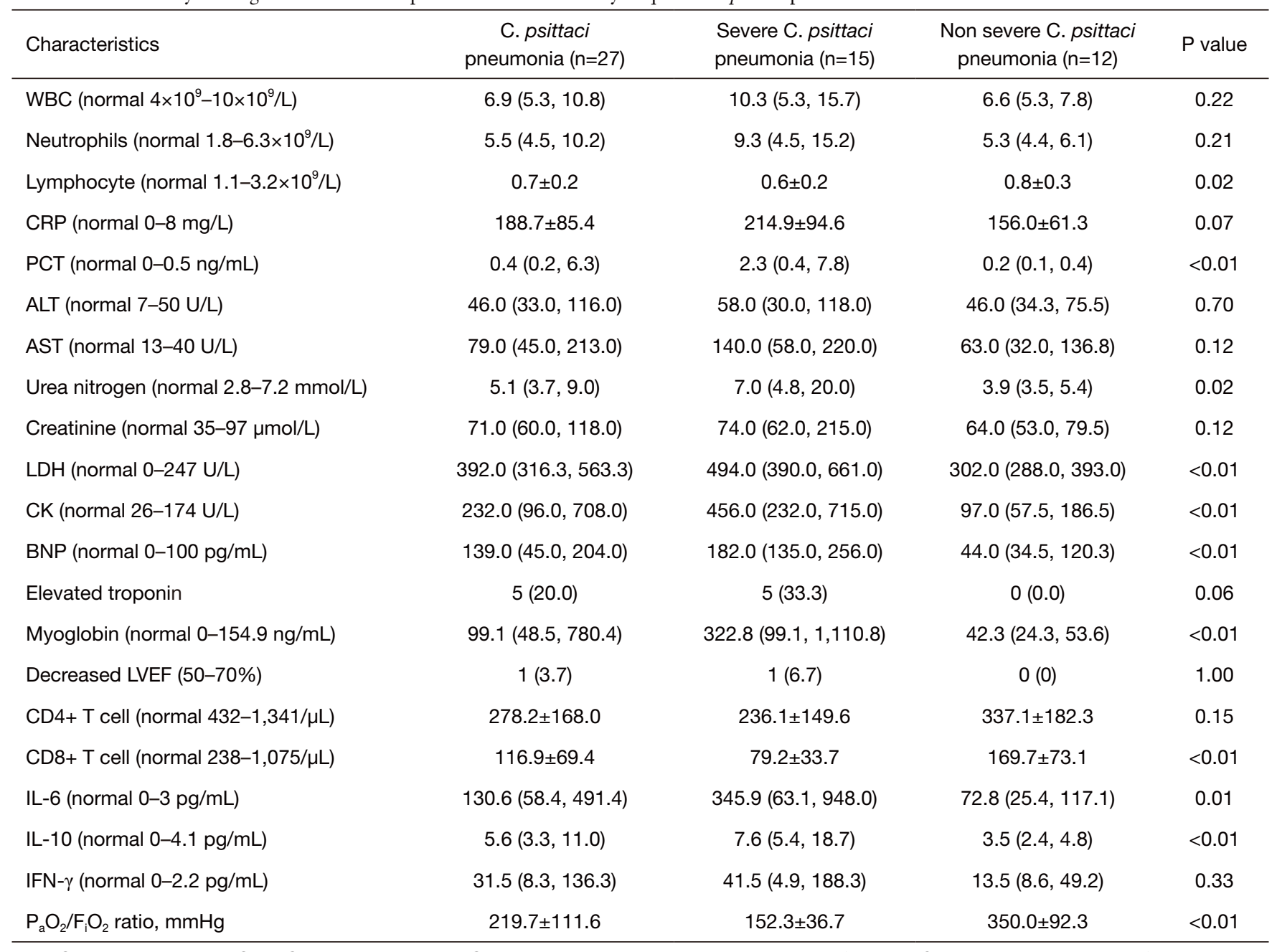

WBC, white blood cell; CRP, C-reactive protein; PCT, procalcitonin; ALT, alanine aminotransferase; AST, aspartate aminotransferase; LDH, lactate dehydrogenase; CK, creatine kinase; BNP, B natriuretic peptide; LVEF, left ventricular ejection fraction.

\section{Risk factors associated with severe C. psittaci pneumonia}

Results from the multivariate analysis indicated that elevated CK and BNP significantly increased the risk of severe $C$. psittaci pneumonia (OR 15.2, 95\% CI: 1.1-204.8, $\mathrm{P}=0.04$; and OR $22.3,95 \% \mathrm{CI}: 1.8-281.9, \mathrm{P}=0.02$, respectively) (Table 6).

\section{Discussion}

In this study, we found that $C$. psittaci pneumonia presented with clinical characteristics, such as non-specific hyperpyrexia, fatigue, and cough, which are similar to pneumonia caused by other pathogens. However, in cases of $C$. psittaci pneumonia, the majority $(85 \%)$ of patients admitted to instances of exposure to birds, which is a crucial diagnostic clue for the development of psittacosis. This condition presents in middleaged adults (average 63 years), and the results in our study were similar to previously reported findings on the disease $(2,16,17)$. However, some characteristics and clinical findings in our study differed from those reported in others. Dyspnea was seen in $70 \%$ of patients in our study, including $100 \%$ of patients with severe disease, which was significantly more frequent than the incidence in the non-severe group, and 53\% of patients with severe infection required invasive medical ventilation. In a study comprising 135 patients with psittacosis, dyspnea was a reported symptom in $24 \%$ of patients, and none developed fulminant multiorgan failure and no fatalities were reported (17). In another endemic study conducted in Australia 
Table 4 Radiological findings on admission of patients with community-acquired C. psittaci pneumonia

\begin{tabular}{|c|c|c|c|c|}
\hline Characteristics & $\begin{array}{c}\text { C. psittaci } \\
\text { pneumonia }(n=27)\end{array}$ & $\begin{array}{l}\text { Severe C. psittaci } \\
\text { pneumonia }(n=15)\end{array}$ & $\begin{array}{l}\text { Non severe C. psittaci } \\
\text { pneumonia }(n=12)\end{array}$ & $P$ value \\
\hline Lobes involvement >2, n (\%) & $7(25.9)$ & $7(46.7)$ & $0(0)$ & 0.01 \\
\hline Inflammatory exudation, n (\%) & $25(92.6)$ & $13(86.7)$ & $12(100)$ & 0.49 \\
\hline Lymphadenopathy, n (\%) & $10(37.0)$ & $7(46.7)$ & $3(25.0)$ & 0.42 \\
\hline Pleural effusions, n (\%) & & & & 0.46 \\
\hline No pleural effusions & $7(25.9)$ & $3(20.0)$ & $4(33.3)$ & \\
\hline
\end{tabular}
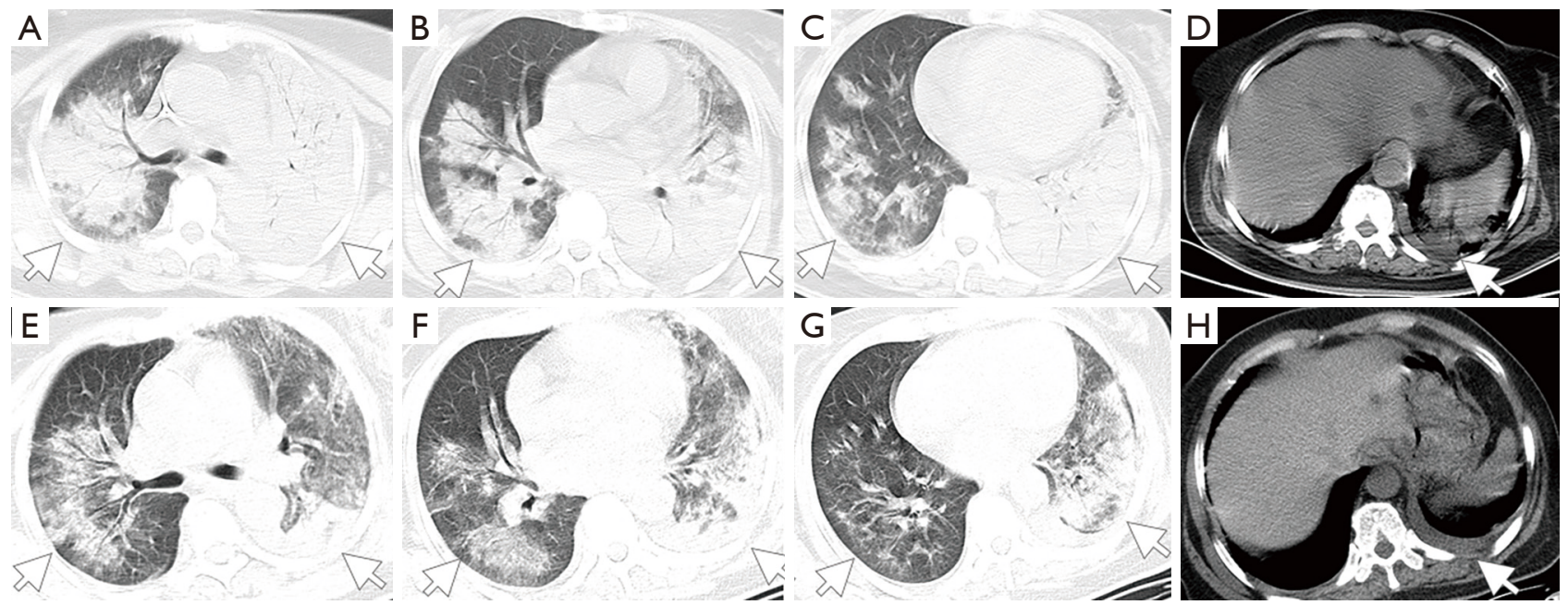

Figure 1 Serial chest computed tomography (CT) scans of a 58-year-old woman with severe C. psittaci pneumonia. The initial CT scan shows air-space consolidation with inflammatory exudates in five lobes of the lung with left small pleural effusion (white arrows) on 2020-4-15, eight days after onset (A,B,C,D). On 2020-4-26, after 11 days of moxifloxacin therapy, a repeat CT scan shows resolution of the consolidation leaving behind ground-glass opacities and inflammatory exudates along with left small pleural effusion (white arrows) (E,F,G,H).

and comprising 44 patients with community-acquired psittacosis, only one patient (2\%) was reported as receiving invasive ventilatory support, and eventually succumbed to respiratory failure (16). However, a recent study focusing on severe pneumonia caused by Chlamydia psittaci reported that $100 \%$ of patients had dyspnea and $66.7 \%$ needed invasive ventilator support, which is consistent with our results (2). Researchers in the Netherlands reviewed the case reports of patients with severe psittacosis requiring respiratory support and found that eight of 12 patients with severe respiratory failure perished (7). Collectively, these findings indicate that respiratory failure requiring ventilatory support is not a rare occurrence and can lead to fatalities.

Laboratory findings in our study showed that PCT, urea nitrogen, LDH, CK, BNP, myoglobin, IL-6, and IL-10 levels were significantly higher, and the lymphocyte and CD8+ $\mathrm{T}$ cell counts, and $\mathrm{P}_{\mathrm{a}} \mathrm{O}_{2} / \mathrm{F}_{\mathrm{i}} \mathrm{O}_{2}$ ratio were lower in patients with the severe form of the infection than in those with the 

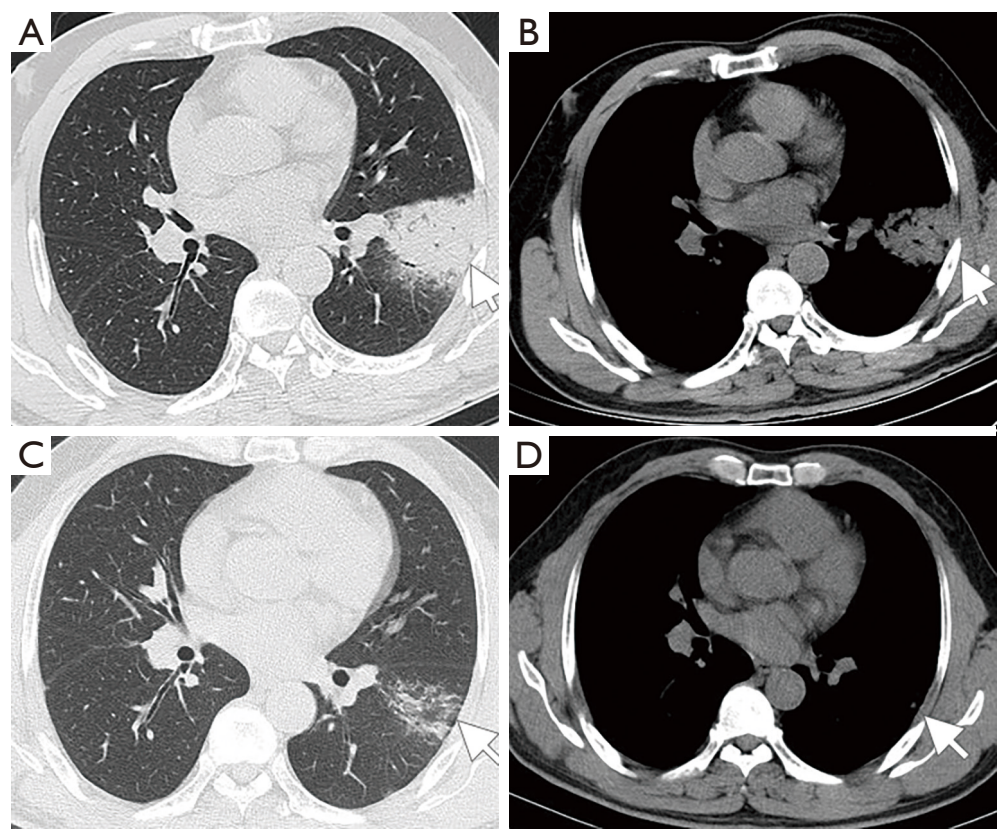

Figure 2 Serial chest CT scans of a 56-year-old man with non-severe C. psittaci pneumonia. The initial CT scan shows consolidation in the lower lobe of the left lung (white arrows) on 2020-7-20, four days after onset (A,B). On 2020-8-3, 18 days after the onset, a repeat CT scan shows almost complete resolution of the consolidation 2 weeks after azithromycin therapy (white arrows) (C,D).

Table 5 Treatment and outcomes of patients with community-acquired C. psittaci pneumonia

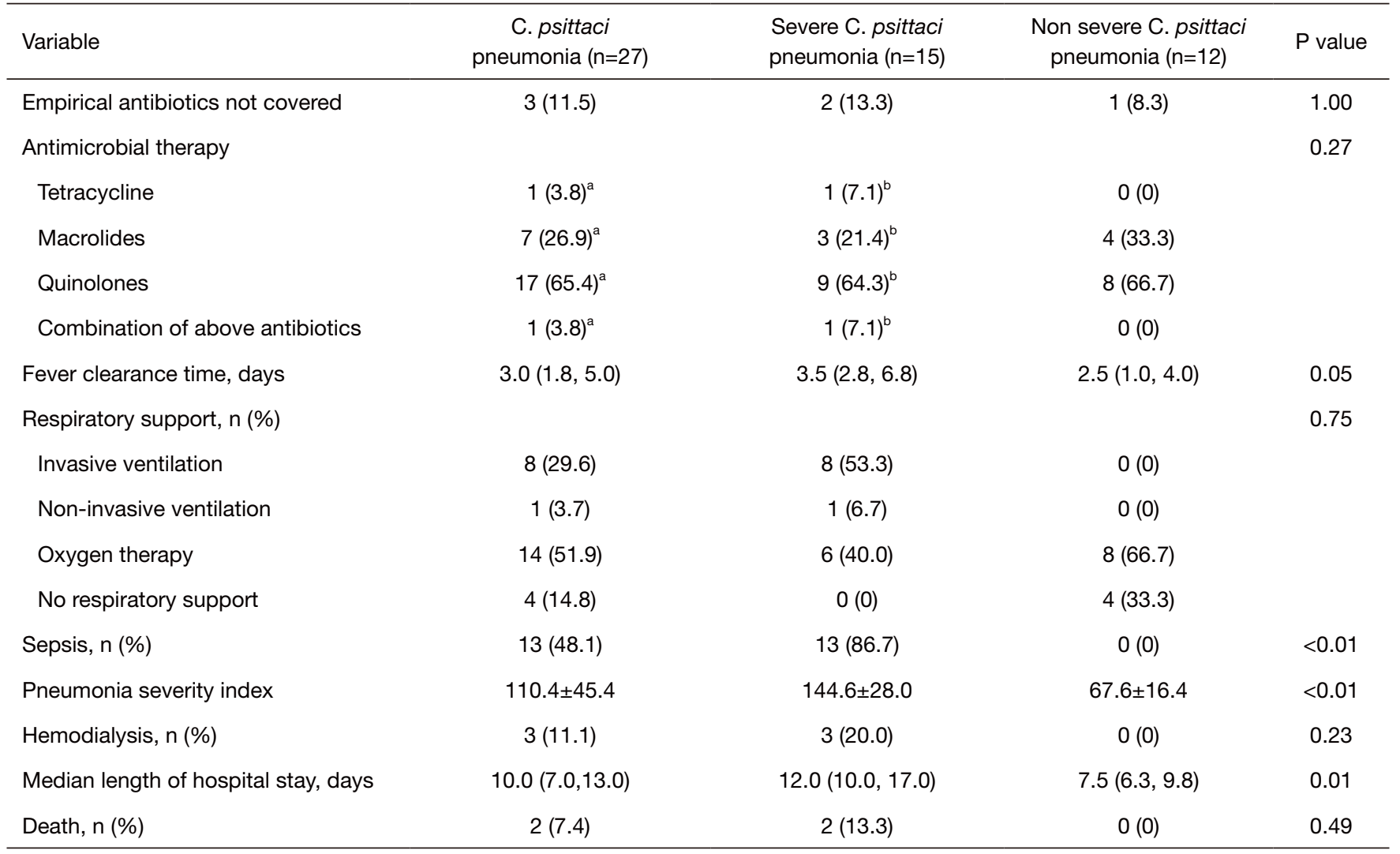

$a=26 ; b=14$. 
Table 6 Multivariate logistic regression analysis of factors associated with severe community-acquired C. psittaci pneumonia

\begin{tabular}{lccc}
\hline Variables & Odds ratio & 95\% confidence interval & P value \\
\hline CK $(>174 \mathrm{U} / \mathrm{L})$ & 15.2 & $1.1-204.8$ & 0.04 \\
$\mathrm{BNP}(>100 \mathrm{pg} / \mathrm{mL})$ & 22.3 & $1.8-281.9$ & 0.02 \\
\hline
\end{tabular}

The area under the curve was 0.88 . CK, creatine kinase; BNP, B natriuretic peptide.

non-severe infection. The independent risk factors associated with severe $C$. psittaci pneumonia were $\mathrm{CK}$ and BNP.

$\mathrm{CK}$ is distributed in many tissues, including cardiac and skeletal muscle. Its lack of specificity has resulted in it not being used in the diagnosis of myocardial damage for several years, despite it being the most sensitive indicator of muscle injury (18). Previously published case reports suggest the occurrence of rhabdomyolysis in psittacosis presented with a high level of CK $(19,20)$, although the mechanism by which this occurs is unknown. Our study shows that psittacosis-associated rhabdomyolysis is not rare both in severe and non-severe groups, and abnormal CK levels (higher than $174 \mathrm{U} / \mathrm{L}$ ) is a predictive factor of severe C. psittaci pneumonia, which indicated the presence of muscle injury in psittacosis patients.

While BNP is a marker for heart failure, it is also thought to be a biomarker to determine the severity and outcome of CAP (21-24), and our results suggest abnormal BNP is also an independent risk factor associated with severe $C$. psittaci pneumonia. BNP secretion is triggered by hypoxia, and its levels are increased in patients with severe sepsis and septic shock (25). Moreover, the activation of proinflammatory cytokines has also been identified as a factor inducing BNP secretion (24). In our study, patients with severe infection were found to have a significantly lower $\mathrm{P}_{\mathrm{a}} \mathrm{O}_{2} / \mathrm{F}_{\mathrm{i}} \mathrm{O}_{2}$ ratio and higher levels of PCT, IL-6, and IL-10 compared to those with non-severe infection. Additionally, $86.7 \%$ of patients with severe infection developed sepsis, whereas none developed septic complications in the non-severe group. Collectively, these data may help interpret the BNP levels.

Involvement of the heart in psittacosis is uncommon, and conditions such as endocarditis, myocarditis, and pericarditis have rarely been reported. Case studies suggest that myocarditis may lead to elevated troponin levels, left ventricular dilatation, and severely decreased left ventricular ejection fraction (LVEF) (26,27). However, in our study, only one patient with severe infection had a decreased LVEF of $45 \%$. Although $33.3 \%$ of patients with severe infection exhibited elevated troponin levels, this increase was not statistically significant compared to those with non- severe infections. We have no direct evidence to prove the occurrence of myocardial injury in our study, and cardiac involvement cannot adequately explain the independent results of CK and BNP levels. Moreover, the serological results indicating the presence of IgM and IgG antibodies for $C$. pneumoniae and $M$. pneumoniae suggest the possibility of cross-reactivity of these diagnostic tests, which is consistent with other findings $(1,28)$.

Based on CT results in our study, $46.7 \%$ of patients with severe infection exhibited involvement of more than two lung lobes. Air-space consolidation, inflammatory exudates, ground-glass opacities, and bronchiectasis were common. Pleural effusions were present in $74 \%$ of patients. This was much higher than the figure reported in an Australian study (13\%) (16), and the $44.4 \%$ seen in a study on severe C. psittaci pneumonia in China (2), and, indicates pleural effusions may be more common than generally reported.

Tetracyclines are first-line antibiotics for the treatment of psittacosis $(9,13)$, and severely ill patients may require intravenous doxycycline, which is unavailable in our hospital. In the present study, 17 patients with psittacosis received quinolones, one of whom succumbed. Another patient with severe psittacosis who died 24 hours after admission, received carbapenem as the initial empirical antibiotic. These findings suggest it may be better to follow the prescribed guidelines and administer a $\beta$-lactam plus a macrolide, or a $\beta$-lactam plus a respiratory fluoroquinolone, before identifying the causative pathogen in patients with severe CAP (29). Owing to the unavailability of doxycycline in the majority of hospitals in China, quinolones are frequently administered as the first choice, and while some experimental models report the efficacy of quinolones in C. psittaci infections, further prospective clinical studies are needed to confirm their efficacy (30).

Our retrospective study has several limitations. Firstly, this was a single-center study in a tertiary teaching hospital, and bias may exist as patients with a mild illness would not have been admitted. Secondly, the sample size was small, and thirdly, the diagnosis of $C$. psittaci pneumonia was made solely using mNGS without confirmation using other 
diagnostic methods. Future studies with a larger population in multiple centers are needed.

\section{Conclusions}

A history of avian exposure in middle-aged patients could be suggestive of $C$. psittaci pneumonia. Respiratory failure is not a rare occurrence and can prove to be fatal. Abnormal $\mathrm{CK}$ and $\mathrm{BNP}$ are independent risk factors for severe $C$. psittaci pneumonia.

\section{Acknowledgments}

The authors would like to thank MJEditor (www.mjeditor. com) for its linguistic assistance during the preparation of this manuscript.

Funding: This work was supported by the Project of National Natural Science Foundation of China (Grant number 81970066).

\section{Footnote}

Reporting Checklist: The authors have completed the STROBE reporting checklist. Available at https://dx.doi. org/10.21037/apm-21-1502

Data Sharing Statement: Available at https://dx.doi. org/10.21037/apm-21-1502

Conflicts of Interest: All authors have completed the ICMJE uniform disclosure form (available at https://dx.doi. org/10.21037/apm-21-1502). The authors have no conflicts of interest to declare.

Ethical Statement: The authors are accountable for all aspects of the work in ensuring that questions related to the accuracy or integrity of any part of the work are appropriately investigated and resolved. This study received approval from the Ethics Committee of the First Affiliated Hospital of Wenzhou Medical University (NO. 2020-111) and was conducted in accordance with the Declaration of Helsinki (as revised in 2013). No informed consent was required due to the retrospective nature of the study.

Open Access Statement: This is an Open Access article distributed in accordance with the Creative Commons Attribution-NonCommercial-NoDerivs 4.0 International License (CC BY-NC-ND 4.0), which permits the non- commercial replication and distribution of the article with the strict proviso that no changes or edits are made and the original work is properly cited (including links to both the formal publication through the relevant DOI and the license). See: https://creativecommons.org/licenses/by-nc-nd/4.0/.

\section{References}

1. Lamoth F, Greub G. Fastidious intracellular bacteria as causal agents of community-acquired pneumonia. Expert Rev Anti Infect Ther 2010;8:775-90.

2. Chen X, Cao K, Wei Y, et al. Metagenomic nextgeneration sequencing in the diagnosis of severe pneumonias caused by Chlamydia psittaci. Infection 2020;48:535-42.

3. Zhang H, Zhan D, Chen D, et al. Next-generation sequencing diagnosis of severe pneumonia from fulminant psittacosis with multiple organ failure: a case report and literature review. Ann Transl Med 2020;8:401.

4. Petrovay F, Balla E. Two fatal cases of psittacosis caused by Chlamydophila psittaci. J Med Microbiol 2008;57:1296-8.

5. Pandeli V, Ernest D. A case of fulminant psittacosis. Crit Care Resusc 2006;8:40-2.

6. Wichert A, Lukasewitz P, Häuser MH, et al. ARDS in fulminant ornithosis and treatment with extracorporeal lung assist. Int J Artif Organs 2000;23:371-4.

7. Verweij PE, Meis JF, Eijk R, et al. Severe human psittacosis requiring artificial ventilation: case report and review. Clin Infect Dis 1995;20:440-2.

8. Hogerwerf L, DE Gier B, Baan B, et al. Chlamydia psittaci (psittacosis) as a cause of community-acquired pneumonia: a systematic review and meta-analysis. Epidemiol Infect 2017;145:3096-105.

9. Balsamo G, Maxted AM, Midla JW, et al. Compendium of Measures to Control Chlamydia psittaci Infection Among Humans (Psittacosis) and Pet Birds (Avian Chlamydiosis), 2017. J Avian Med Surg 2017;31:262-82.

10. Gu L, Liu W, Ru M, et al. The application of metagenomic next-generation sequencing in diagnosing Chlamydia psittaci pneumonia: a report of five cases. BMC Pulm Med 2020;20:65.

11. Kong CY, Zhu J, Lu JJ, et al. Clinical characteristics of Chlamydia psittaci pneumonia. Chin Med J (Engl) 2021;134:353-5.

12. Wen W, Gu L, Zhao LW, et al. Diagnosis and treatment of Chlamydia psittaci pneumonia: experiences of 8 cases. Zhonghua Jie He He Hu Xi Za Zhi 2021;44:531-6. 
13. Mandell LA, Wunderink RG, Anzueto A, et al. Infectious Diseases Society of America/American Thoracic Society consensus guidelines on the management of communityacquired pneumonia in adults. Clin Infect Dis 2007;44 Suppl 2:S27-72.

14. Miao Q, Ma Y, Wang Q, et al. Microbiological Diagnostic Performance of Metagenomic Next-generation Sequencing When Applied to Clinical Practice. Clin Infect Dis 2018;67:S231-40.

15. Cabral BMI, Edding SN, Portocarrero JP, Lerma EV. Rhabdomyolysis. Dis Mon 2020;66:101015.

16. Branley JM, Weston KM, England J, et al. Clinical features of endemic community-acquired psittacosis. New Microbes New Infect 2014;2:7-12.

17. Yung AP, Grayson ML. Psittacosis--a review of 135 cases. Med J Aust 1988;148:228-33.

18. Bohlmeyer TJ, Wu AH, Perryman MB. Evaluation of laboratory tests as a guide to diagnosis and therapy of myositis. Rheum Dis Clin North Am 1994;20:845-56.

19. Matsushima H, Takayanagi N, Ubukata M, et al. A case of fulminant psittacosis with rhabdomyolysis. Nihon Kokyuki Gakkai Zasshi 2002;40:612-6.

20. Kawamura S, Ikematsu H, Ogimoto H. Two cases of psittacosis accompanied with rhabdomyolysis. Kansenshogaku Zasshi 1990;64:1239-43.

21. Usuda D, Sangen R, Hashimoto Y, et al. Validation of a B-type natriuretic peptide as a prognostic marker in pneumonia patients: a prospective cohort study. BMJ Open 2016;6:e010440.

22. Li J, Ye H, Zhao L. B-type natriuretic peptide in predicting the severity of community-acquired pneumonia. World J Emerg Med 2015;6:131-6.

Cite this article as: Su S, Su X, Zhou L, Lin P, Chen J, Chen C, Zhou Y, Li Y. Severe Chlamydia psittaci pneumonia: clinical characteristics and risk factors. Ann Palliat Med 2021;10(7):80518060. doi: 10.21037/apm-21-1502
23. Nowak A, Breidthardt T, Christ-Crain M, et al. Direct comparison of three natriuretic peptides for prediction of short- and long-term mortality in patients with community-acquired pneumonia. Chest 2012;141:974-82.

24. Christ-Crain M, Breidthardt T, Stolz D, et al. Use of B-type natriuretic peptide in the risk stratification of community-acquired pneumonia. J Intern Med 2008;264:166-76.

25. Post F, Weilemann LS, Messow CM, et al. B-type natriuretic peptide as a marker for sepsis-induced myocardial depression in intensive care patients. Crit Care Med 2008;36:3030-7.

26. Walder G, Gritsch W, Wiedermann CJ, et al. Co-infection with two Chlamydophila species in a case of fulminant myocarditis. Crit Care Med 2007;35:623-6.

27. Schinkel AF, Bax JJ, van der Wall EE, et al. Echocardiographic follow-up of Chlamydia psittaci myocarditis. Chest 2000;117:1203-5.

28. Cillóniz C, Torres A, Niederman M, et al. Communityacquired pneumonia related to intracellular pathogens. Intensive Care Med 2016;42:1374-86.

29. Metlay JP, Waterer GW, Long AC, et al. Diagnosis and Treatment of Adults with Community-acquired Pneumonia. An Official Clinical Practice Guideline of the American Thoracic Society and Infectious Diseases Society of America. Am J Respir Crit Care Med 2019;200:e45-67.

30. Stewardson AJ, Grayson ML. Psittacosis. Infect Dis Clin North Am 2010;24:7-25.

(English Language Editor: B. Draper) 
Supplementary

Table S1 Detail mNGS results of 27 cases

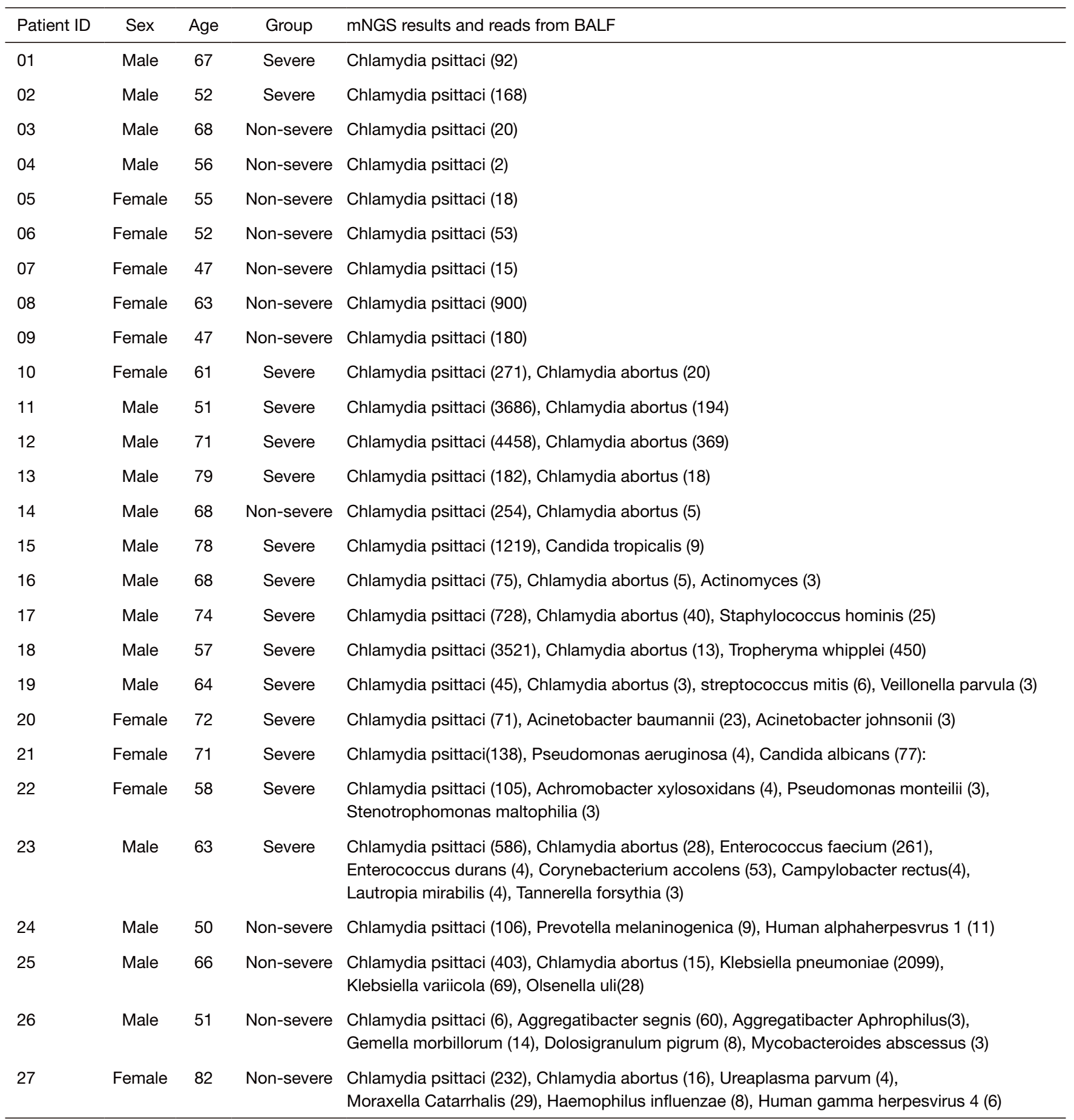

